\title{
Effect of hysterectomy on anorectal and urethrovesical physiology
}

\author{
A Prior, K Stanley, A R B Smith, N W Read
}

\begin{abstract}
To investigate whether vaginal or total abdominal hysterectomy is associated with changes in anorectal and urethrovesical physiology, 26 women were studied before operation and six weeks and six months afterwards. The results showed a postoperative increase in both rectal and vesical sensitivity $(\mathbf{p}<0.01)$. Similar results were observed irrespective of the type of hysterectomy. No significant changes in rectal or bladder compliance were noted, and anal pressure and urethral pressure and length were unchanged after surgery. Whole gut transit was not affected by hysterectomy. Urinary symptoms occurred de novo in 6/26 women and gastrointestinal symptoms in 2/26 women. These results show that significant changes in rectal and vesical sensitivity occur after hysterectomy for benign disease. These persist for at least six months postoperatively but are not always associated with development of urinary or gastrointestinal symptoms.
\end{abstract}

Women often date the onset of bowel and bladder dysfunction to previous hysterectomy but no prospective studies have been published on the effect of total hysterectomy on either anorectal or vesical physiology. One retrospective study' has shown a decrease in the frequency of defecation after total abdominal hysterectomy, and it was suggested that this may reflect autonomic denervation occurring at surgery. However, physiological studies of colorectal function in women with constipation after hysterectomy have produced inconsistent results - one showed decreased rectal sensitivity and sigmoid motility, ${ }^{2}$ whereas another found no differences in either sensitivity or motor activity. ${ }^{3}$

It is generally agreed that a reduction in bladder sensitivity and a temporary increase in bladder tone are common after radical hysterectomy. ${ }^{+11}$ However, only two studies have reported urodynamic function after hysterectomy for benign disease. One of these reported an increase in bladder sensitivity and tone in the

Gastrointestinal

Hallamshire Hospital,

Sheffield

A Prior

N W Read

Department of Obstetrics and Gynaecology, Jessop

Hospital for Women,

Sheffield

K Stanley

A R B Smith

Correspondence to:

Dr A Prior, Department of

Medicine, University Hospital

of South Manchester,

Manchester M20 8LR.

Accepted for publication

3 June 1991 initial postoperative period with a return to normal function by four weeks, ${ }^{12}$ whereas the other found no significant changes in bladder and urethral function at four weeks and four months after hysterectomy. ${ }^{13}$ The occurrence of new urinary symptoms after abdominal or vaginal hysterectomy $y^{1+15}$ is also controversial.

The purpose of this study was to assess prospectively both anorectal and urethrovesical function in women undergoing total abdominal or vaginal hysterectomy.

\section{Methods}

\section{PATIENTS}

The study group consisted of 26 patients, whose characteristics are summarised in Table I. The mean age of the patients was 43 years (range 2854 years) and all but two were premenopausal. The commonest reasons for surgery were dysfunctional uterine bleeding and fibroids. Eighteen of the patients had a vaginal hysterectomy and eight underwent total abdominal hysterectomy, with preservation of ovarian function in all. The route chosen represented surgical preference.

\section{SYMPTOMATIC ASSESSMENT}

A detailed urological and gastrointestinal history was taken from each patient, noting particularly the frequency and urgency of micturition, nocturia, stress incontinence, non-menstrual abdominal pain, abdominal distension, and any disturbance of bowel habit. Constipation was defined as less than three stools per week or frequent straining, and diarrhoea as three or more loose stools per day. Urinary frequency was defined as a micturition frequency of greater than seven times during the day, and urgency as an inability to delay micturition for longer than five minutes after the urge to void.

\section{PHYSIOLOGICAL ASSESSMENT}

The physiological assessment of bladder, urethra, and anorectum were performed on the same study day. With the subject supine, a multilumen silastic catheter was placed in the bladder so that the recording side holes were positioned $1 \cdot 5,2,2 \cdot 5,3$, and $6 \mathrm{~cm}$ from the external urethral meatus, and a multilumen polyvinyl catheter was inserted into the rectum with side holes $0 \cdot 5,1 \cdot 5,2 \cdot 5,4$, and $14 \mathrm{~cm}$ from the anal verge. A latex balloon was attached to the rectal catheter between 6 and $11 \mathrm{~cm}$ from the anal verge with a non-perfused side hole positioned at $8 \mathrm{~cm}$. With the exception of the side hole within the balloon, each recording channel 
was perfused with water at a rate of $0.2 \mathrm{ml}$ per minute (Arndorfer Medical Specialties Inc) and linked via water filled transducers to a pen recorder (Ormed Ltd) allowing simultaneous measurement of bladder, urethral, rectal, and anal pressures throughout the study. The rectal balloon channel was filled with air and connected to an air filled transducer.

\section{EXPERIMENTAL PROTOCOL}

After a basal period of 15 minutes, a urethral pressure profile was obtained using a 'pull through' technique. Filling cystometry was then performed with sterile water at room temperature at a rate of $50 \mathrm{ml}$ per minute. Patients indicated the sensations of first desire and strong desire to micturate, and the infusion was stopped when maximum capacity was reached. After voiding there was a further basal period of 15 minutes and then the rectal balloon was serially inflated with air at 10,20,40,60,100,150, 200, and $250 \mathrm{ml}$ until the patient complained of discomfort. Each inflation was maintained for one minute, and was separated from the next by a period of one minute. At each volume the patients were asked whether they felt the distension and if so whether the sensation was that of gas, desire to defecate, urgent desire to defecate, or discomfort.

The following indices were derived from the anorectal recordings:

(a) Maximum anal basal pressure;

(b) The lowest rectal volume required to induced internal anal sphincter relaxation and to cause relaxation sustained throughout the period of distension;

(c) The lowest rectal volumes required to produce the sensations of gas, desire to defecate, urgency of defecation, and discomfort;

(d) Rectal compliance calculated from the volume:pressure relation at $100 \mathrm{ml}$ distension;

(e) Rectal motility index calculated by summing the area under the rectal pressure profiles during each distension at 4 and $14 \mathrm{~cm}$ from the anal verge.

The following measurements were obtained from the urodynamic studies:

(a) The lowest bladder volume required to induce a desire to micturate, a strong desire to micturate, and maximum capacity;

(b) The intravesical pressure rise from zero to maximum capacity and the bladder compliance calculated from the volume:pressure relation at $250 \mathrm{ml}$ distension;

(c) Maximum urethral closure pressure;

TABLE II Results (mean (SEM)) of anorectal studies

\begin{tabular}{lcccc}
\hline & $\begin{array}{l}\text { Before } \\
\text { operation }\end{array}$ & $\begin{array}{l}\text { After } \\
6 \text { weeks }\end{array}$ & $\begin{array}{l}\text { After } \\
6 \text { months }\end{array}$ & $\begin{array}{l}\text { Control } \\
\text { values }\end{array}$ \\
\hline Rectal sensation $(\mathrm{ml}):$ & & & & \\
$\quad$ Gas & $40(5)$ & $24(3)^{\star \star}$ & $22(3)^{\star \star}$ & $42(7)$ \\
$\quad$ Desire to defecate & $86(9)$ & $57(6)^{\star \star}$ & $50(6)^{\star \star}$ & $87(8)$ \\
$\quad$ Urgency & $132(9)$ & $91(9)^{\star \star}$ & $82(6)^{\star \star}$ & $151(10)$ \\
$\quad$ Discomfort & $160(9)$ & $115(9)^{\star \star}$ & $107(8)^{\star \star}$ & $175(12)$ \\
Rectal compliance $\left(\mathrm{ml} / \mathrm{cm} \mathrm{H}_{2} \mathrm{O}\right)$ & $11 \cdot 0(1 \cdot 3)$ & $11 \cdot 4(1 \cdot 8)$ & $9 \cdot 5(1 \cdot 1)$ & $9 \cdot 1(0 \cdot 9)$ \\
Rectal motility index & $146(25)$ & $163(38)$ & $153(37)$ & $192(38)$ \\
Max basal anal pressure $\left(\mathrm{cm} \mathrm{H}_{2} \mathrm{O}\right)$ & $114(8)$ & $118(6)$ & $122(6)$ & $106(6)$ \\
Threshold internal anal sphincter relaxation $(\mathrm{ml})$ & $22(3)$ & $22(3)$ & $24(5)$ & $26(4)$ \\
Sustained internal anal sphincter relaxation $(\mathrm{ml})$ & $110(13)$ & $100(10)$ & $100(10)$ & $83(11)$ \\
\hline
\end{tabular}

$\star$ Normal female values for our laboratory (age matched).

${ }^{\star} \mathrm{p}<0.01$ postoperative $v$ preoperative

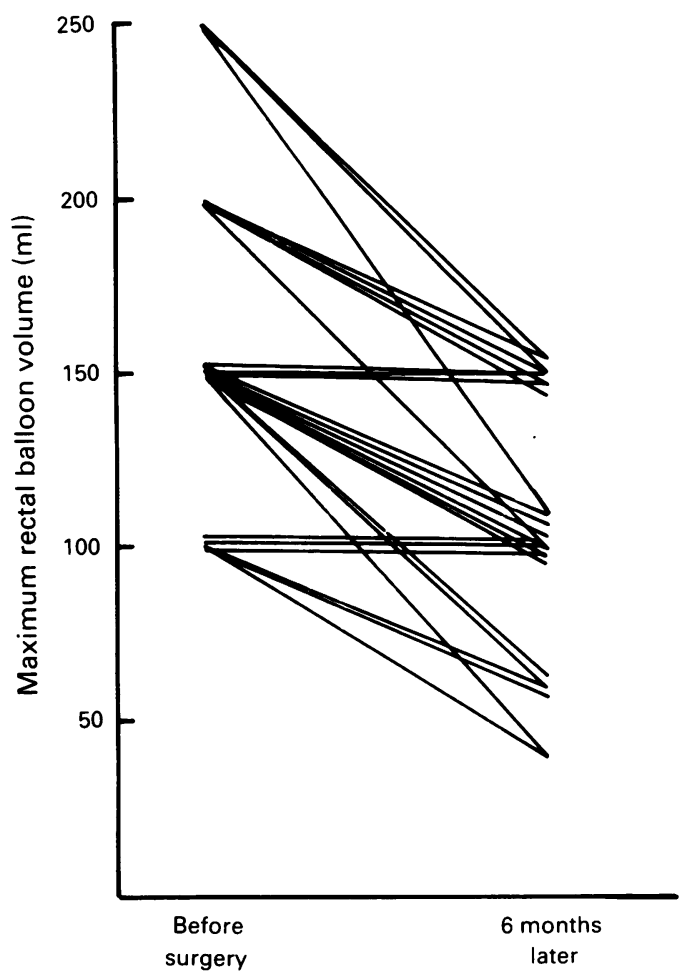

Figure 1: Individual changes in maximum tolerated rectal balloon volume after hysterectomy.

(d) Functional urethral length.

Whole gut transit was assessed on the day after the physiological study using a dye technique in which a capsule containing 'brilliant blue' dye was ingested at 9 am and patients recorded the time of the first appearance of the colour in the stools. This has been shown to correlate with $x$ ray marker techniques ${ }^{16}$ and was preferred because it did not involve extra visits to hospital and did not expose the patients to radiation.

\section{STATISTICAL ANALYSIS}

The difference between the physiological measurements before and after operation was assessed using the Wilcoxan signed rank test with significance set at the $5 \%$ level.

\section{ETHICAL CONSIDERATIONS}

All patients gave informed consent for the study which was approved by the Southern Sheffield District Ethical Committee.

\section{Results}

\section{PHYSIOLOGY}

Rectal sensation before surgery fell within the normal range for women in our laboratory (Table II). Hysterectomy was followed by significant increases in rectal sensitivity (Table II and Fig 1). The threshold volumes required to induce the sensations of gas, desire to defecate, urgency, and discomfort were significantly reduced at six weeks after operation and this reduction was maintained at six months $(p<0.01)$. Other aspects of anorectal physiology such as rectal compliance, rectal motor activity induced by distension, and anal pressures, and thresholds for relaxation were unchanged after surgery 
TABLE III Results (mean (SEM)) of urodynamic studies

\begin{tabular}{lccc}
\hline & $\begin{array}{l}\text { Before } \\
\text { operation }\end{array}$ & $\begin{array}{l}\text { After } \\
6 \text { weeks }\end{array}$ & $\begin{array}{l}\text { After } \\
6 \text { months }\end{array}$ \\
\hline Bladder sensation $(\mathrm{ml}):$ & & & \\
$\quad$ First desire & $298(22)$ & $263(21)$ & $237(22)^{\star \star}$ \\
$\quad$ Urgency & $424(33)$ & $387(32)$ & $353(29)^{\star \star}$ \\
Maximum capacity & $462(32)$ & $352(29)$ & $379(29)^{\star \star}$ \\
Intravesical pressure increase $(0-\max )\left(\mathrm{cm} \mathrm{H}_{2} \mathrm{O}\right)$ & $6 \cdot 3(0 \cdot 7)$ & $6 \cdot 4(0 \cdot 6)$ & $6 \cdot 6(0 \cdot 6)$ \\
Bladder compliance $\left(\mathrm{ml} / \mathrm{cm} \mathrm{H}_{2} \mathrm{O}\right)$ & $59 \cdot 2(6 \cdot 4)$ & $58 \cdot 2(6 \cdot 7)$ & $55 \cdot 2(6 \cdot 5)$ \\
Urethral length $(\mathrm{cm})$ & $3 \cdot 3(0 \cdot 1)$ & $3 \cdot 2(0 \cdot 1)$ & $3 \cdot 2(0 \cdot 1)$ \\
Maximum urethral pressure $\left(\mathrm{cm} \mathrm{H}_{2} \mathrm{O}\right)$ & $96(4)$ & $93(4)$ & $93(4)$ \\
\hline
\end{tabular}

$\star \star \mathrm{p}<0.016$ months postoperative $v$ preoperative.

(Table II). There were no significant differences between the results after vaginal and abdominal hysterectomy.

A corresponding increase in bladder sensitivity also followed hysterectomy. Threshold bladder volumes required to induce first desire to micturate, strong desire to micturate, and maximum capacity were all reduced (Table III and Fig 2), although significant changes were noted only at six months. The intravesical pressure increase during filling, bladder compliance, urethral functional length, and maximum urethral pressure were unchanged after hysterectomy (Table III). One patient developed detrusor instability six months after operation, exhibiting spontaneous contractile activity at 140 $\mathrm{ml}$. No significant differences were found between the results from patients undergoing vaginal or abdominal hysterectomies.

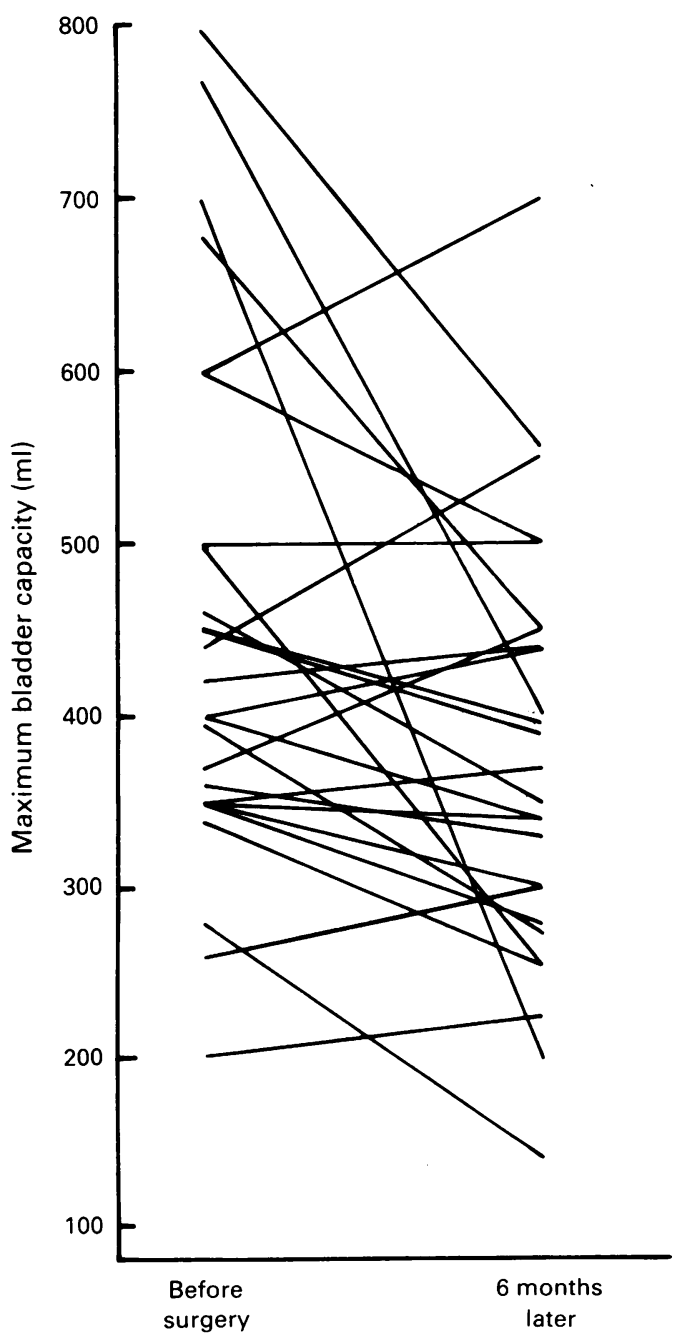

TRANSIT TIME

No significant changes in whole gut transit times occurred after hysterectomy (preoperative 32 (4) hours, six weeks 35 (5) hours, six months 32 (4) hours, mean (SEM)).

\section{DE NOVO SYMPTOMS}

Bowel dysfunction together with pain and distension occurred for the first time after operation in two patients. In both cases the symptoms were mild, and in one seemed transient, having resolved by six months.

Urinary frequency or urgency, or both, developed for the first time after hysterectomy in six patients, although this was transient in two of these.

\section{CORRELATION OF PERIOPERATIVE FACTORS,} SYMPTOMS, AND PHYSIOLOGY

Examination of patients' records showed no clear association between any perioperative factors and postoperative reduction in bladder volume. Of the total patient group, seven patients had indwelling catheters for longer than 24 hours, and five of these developed a greater than $20 \%$ reduction in bladder capacity after operation. However, 5 of 11 patients who did not have indwelling catheters also developed a reduction in bladder capacity. Similarly, of the seven women with postoperative urinary tract infections, only one was found to have a decrease in bladder volume.

Decreased bladder and rectal capacity tended to occur in the same patients. Of the 11 subjects with a greater than $20 \%$ decrease in maximum bladder capacity at six months, nine also had a greater than $20 \%$ reduction in rectal volume to discomfort, and only two patients had a decreased rectal capacity with no change in bladder volume.

\section{Discussion}

The results of this study show that a significant increase in both rectal and bladder sensitivity occurs in some women after hysterectomy for benign disease. The changes are maintained over a six month period after operation but are not associated with any changes in rectal or vesical motor activity and are not always associated with the development of urinary or gastrointestinal symptoms.

The mechanism by which hysterectomy might cause symptoms and influence rectal and vesical physiology remains unclear. One explanation has been that autonomic denervation occurs as a result of damage to the pelvic plexus. ${ }^{\text {T }}$ The autonomic supply to the bladder and lower bowel is closely related to the cardinal and uterosacral ligaments and the upper third of the vagina, and is therefore prone to injury during radical hysterectomy. ${ }^{17}$ Thus, although neurological damage is probably the cause of the decrease in bladder sensitivity and compliance after this radical procedure, ${ }^{+11}$ there should be little risk of damage to the pelvic plexus during a total hysterectomy. ${ }^{17}$ The lack of any changes in rectal and bladder compliance and motor activity 
noted in the present study would support this, and the increase in rectal and bladder sensitivity observed are the reverse of those which occur after autonomic denervation.

The possibility that local trauma, infection, and oedema are responsible for the increase in the sensitivity of the pelvic organs after total hysterectomy is unlikely for several reasons. Firstly, the changes in sensitivity were not accompanied by changes in compliance noted in previous studies performed in the immediate postoperative period. Secondly, no clear association was found between postoperative catheterisation or urinary tract infection and an increase in bladder sensitivity. Thirdly, the changes persisted over six months, by which time local oedema and inflammation should have settled.

It is possible that vesical and rectal sensitivity was abnormal before hysterectomy, and that surgery led to a return to normal sensitivity. This is unlikely as far as rectal sensitivity is concerned since thresholds for rectal sensations were within the normal range for our laboratory preoperatively in all patients, and abnormally low after surgery. It is not possible to comment on bladder sensitivity because of the paucity of data available on the normal threshold volumes for bladder sensation and the dependence of the results on the techniques used during urodynamics. ${ }^{18}$

Some patients may experience psychological changes after hysterectomy. ${ }^{19}$ Physiological studies of patients with irritable bowel syndrome have suggested that anxiety may be associated with an increase in rectal sensitivity. ${ }^{20}$ It is thus possible that an increase in anxiety could explain the changes in rectal sensitivity noted after hysterectomy in the present study. Although no formal measures of anxiety were performed during the study, both clinical observation and the subjects own assessment was that anxiety regarding the urodynamic and anorectal study decreased after the initial visit. Rectal sensory thresholds have been shown to be reproducible in the same subject over a period of time ${ }^{20}$ and it is thus also unlikely that the results simply represent familiarisation with the procedure.

In conclusion, the aetiology of the increase in rectal and vesical sensitivity that occurs in some women after vaginal and abdominal hysterectomy is unclear. It may be that removal of a major pelvic organ with its associated nerve supply alters the gating of sensations from adjacent organs. The increases in sensitivity may underlie the development of bowel and bladder dysfunction in some patients, but cannot account for the severe slow transit constipation ${ }^{23}$ that seems to occur in some women after hysterectomy.

1 Taylor T, Smith AN. Effect of hysterectomy on bowel function. $B M \mathcal{F}$ 1989; 299: 300-1

2 Varma JS, Smith AN. Abnormalities of colo-rectal function in intractable constipation following hysterectomy. Gut 1985 26: $581-2$.

3 Roe AM, Bartolo DCC, McC Mortensen NJ. Slow transit constipation. Comparison between patients with or without previous hysterectomy. Dig Dis Sci 1988; 33: 1159-63.

4 Roman-Lopez JJ, Barclay DL. Bladder dysfunction following Schauta hysterectomy. Am $\mathcal{f}$ Obstet Gynecol 1973; 115: 81-90.

5 Seski JC, Diokno AC. Bladder dysfunction after radical hysterectomy. Am $\mathcal{F}$ Obstet Gynecol 1977; 128: 643-8.

6 Forney JP. The effects of radical hysterectomy on bladder physiology. Am f Obstet Gynecol 1980;138: 374-82.

7 Low JA, Mauger GM, Carmichael JA. The effects of Wertheim hysterectomy on bladder and urethral function. Am F Obstet Gynecol 1981; 139: 826-30.

8 Sasaki H, Yoshida T, Noda K, Yachiku S, Minami K, Kaneko $\mathrm{S}$. Urethral pressure profiles following radical hysterectomy. Obstet Gynecol 1982; 59: 101-4.

9 Carenza L, Nobili S, Giacobini S. Voiding discorders after radical hysterectomy. Gynecol Oncol 1982;13: 213-9.

10 Scotti RJ, Bergman A, Bhatia NN, Ostergard DR Urodynamic changes in urethrovesical function after radical hysterectomy. Obstet Gynecol 1986; 68: 111-9.

11 Farquharson DIM, Shingleton HM, Orr JW, Hatch KD, Hester S, Soong S-J. The short term effect of radical hysterectomy on urethral and bladder function. Brf Obstet Gynaecol 1987; 94: 351-7.

12 Wake CR. The immediate effect of abdominal hysterectomy on intravesical pressure and detrusor activity. Br $\mathcal{F}$ Obstet Gynaecol 1980; 87: 901-2.

13 Langer R, Neuman M, Ron-El R, Golan A, Bukovsky I, Capsi $\mathrm{E}$. The effect of total abdominal hysterectomy on bladder function in asymptomatic women. Obstet Gynecol 1989; 74: 205-7.

14 Hanley HG. The late urological complications of total hysterectomy. Brf Urol 1969; 41: 682-4.

15 Jequier AM. Urinary symptoms and total hysterectomy. Br ₹ Urol 1976; 48: 437-41.

16 Hinton JM, Lennard-Jones JE, Young AC. A new method for studying gut transit times using radopopaque markers. Gut 1969;19: 842-7.

17 Mundy AR. An anatomical explanation for bladder dysfunction following rectal and uterine dysfunction. Br $\mathcal{F}$ Urol tion following recte

18 Abrams PH, Feneley RCL, Torrens M. Urodynamics. Berlin: Springer-Verlag, 1983

19 Oates M, Gath D. Psychological aspects of gynaecological surgery. Ballieres Clin Obstet Gynaecol 1989; 3: 729-49.

20 Prior A, Maxton DG, Whorwell PJ. Anorectal manometry in irritable bowel syndrome: differences between diarrhoea and constipation predominant subjects. Gut 1990; 31: 45862 . 